\title{
Corrosion Inhibitive Effect of Ocimum Gratissimum Extract on Zinc - Aluminium Alloy in Hydrochloric Acid
}

\author{
Mojisola O. Nkiko* and Janet T. Bamgbose \\ Department of Chemistry, University of Agriculture, Pmb 2240, Abeokuta, Nigeria
}

Received 6 May 2011; accepted 26 November 2011

\begin{abstract}
The inhibitive effect of ocimum gratissimum by seed extract on the corrosion of zinc aluminium (ZA) alloy in $2 \mathrm{M}$ hydrochloric acid $(\mathrm{HCl})$ solution has been studied using gravimetric methods. Inhibition increases with concentration of extract but decreases with temperature. This observation implies that ocimum gratissimum seed extract is an effective and non toxic inhibitor of the corrosion of zinc - aluminium alloy. Adsorption of the extract on the surface obeyed the Freundlich adsorption isotherm. The calculated rate constant $(\mathrm{k})$ shows a first order kinetics in the absence and presence of the inhibitor. The kinetic parameter $\mathrm{B}$, measured for the reaction has a high negative value which implies that ocimum gratissimum becomes more effective as the temperature increases. Synergistic effect of halide additives shows an increase in the efficiency of the extract. However synergism parameter shows that synergism of halide additives decreases with increased concentration of inhibitor.
\end{abstract}

Keywords: corrosion inhibitor, gravimetric methods, inhibitor efficiency, ocimum gratissimum, synergism.

\section{Introduction}

The current trend of using zinc - aluminium alloy as an alternative to pure aluminium or zinc for fabrication of materials such as roofing sheets has kindled interest in the study of the properties of zinc - aluminium alloys. Zinc aluminium alloys consist of varying composition of zinc and aluminium which were originally designed for gravity casting. Distinguishing features of the alloys has been reported to include high as - cast strength, excellent bearing properties and low energy requirements for melting $[1,2]$.

\footnotetext{
* Corresponding author. E-mail address: chrismoj3@yahoo.co.uk
} 
Pure aluminium is known for its passivity and excellent corrosion resistance, which make it a primary metal of commerce [3]. However, pure zinc reacts slowly at room temperature with acids. Strong acids such as hydrochloric acid are capable of removing the passive layer and subsequently their reaction with water releases hydrogen gas [4]. Zinc has its major application in corrosion in the plating of steel as a sacrificial metal ${ }^{4}$.

Ekuma et al. [5,6] have studied the service performance of aluminium - zinc alloys in various concentrations of sulphuric acid and have shown that the presence of zinc in aluminium acts as impurity and thus reduces the degree to which aluminium resists to corrosion in the stimulated environment.

The use of naturally occurring substances of plant and animal origin, known as green inhibitors, has generated much interest in recent times. These plant/ animal extracts are cheap, abundant, less toxic, readily available and environmentally friendly [7].

Recent investigations have shown the corrosion inhibitive effect of extracts from local plants such as gum from Dacroydes rdulis [7], opuntia [10], guar gum [11], mumosa tannin [12] and hibiscus sabdariffa [13], just to mention a few, exhibiting good inhibitor efficiencies on the corrosion of different metals, as reported by various authors [7-13]. Eddy et al. [14] has investigated the inhibitive properties of ocimum gratissium on the corrosion of mild steel in sulphuric acid. The present study investigates the inhibitive properties of the species ocimum gratissimum known as African basil.

Ocimum gratissimum belongs to the laminaceae family. Phytochemical screening of the plant has shown that it consists of alkaloids, flavonoids and tannins [15].

\section{Experimental}

\section{Materials and preparation}

Zinc - aluminium alloy was obtained from Midland Galvanizing Products Ltd, Abeokuta, Nigeria.

The weight percentage composition of the zinc - aluminium alloy was determined to be $30 \%$ aluminium and $70 \%$ zinc. Each sheet was mechanically pressed and cut into coupons of dimension $3 \mathrm{~cm}$ by $1.5 \mathrm{~cm}$. Surface treatment of polished coupons involved degreasing with absolute ethanol followed by acetone and dried. The coupons were thereafter stored in a moisture-free desiccator to avoid contamination prior to use.

All chemicals and reagents used were BDH grade. Blank corrodent is $2 \mathrm{M} \mathrm{HCl}$ solution. The inhibitor is an extract of ocimum gratissimum seeds collected from the flora of Ago - Iwoye, Ogun state of Nigeria, and classified at the Forest Research Institute of Nigeria. FHI number 108361.

Stock solution of the plant extract was prepared by placing $0.5 \mathrm{~kg}$ of milled seeds in $100 \mathrm{~mL}$ of $2.0 \mathrm{M}$ hydrochloric acid and refluxed for 2.5 hours. The resulting solution was cooled, filtered and stored. Inhibitor test solutions (v/v) of the extract were prepared in the concentration range of $4 \%-10 \%$. The effect of halide additives was studied by combining $5.0 \mathrm{mM}$ of the salts of $\mathrm{KCl}$ and $\mathrm{KI}$, respectively, with solutions of $10 \%$ extract. Previously prepared coupons of zinc 
- aluminium alloy were weighed and immersed in $100 \mathrm{~mL}$ of different concentrations of the test solution. The coupons were retrieved from the solution every 30 hours, washed and reweighed. The differences in weight of the coupons were taken as the weight loss evaluated in grams.

The inhibitor efficiency of ocimum gratissimum in $2 \mathrm{M} \mathrm{HCl}$ was calculated using the equation

$$
I \%=\frac{W_{0}-W_{i}}{W_{0}} \times 100
$$

where $\mathrm{W}_{\mathrm{i}}$ and $\mathrm{W}_{\mathrm{o}}$ are weight losses of the zinc - aluminium coupons in the presence and absence of the inhibitors, respectively, at the same temperature.

The degree of surface coverage (S) was calculated using the equation

$$
S=\frac{W_{0}-W_{i}}{W_{0}}
$$

\section{Results and discussion}

\section{Temperature dependence of corrosion of $A l-Z n$}

Figure 1 shows the temperature dependence of corrosion of $\mathrm{Al}-\mathrm{Zn}$ alloy. An increase in weight loss of the alloy was observed as the temperature increased from $30{ }^{\circ} \mathrm{C}$ to $60{ }^{\circ} \mathrm{C}$. This implies that the corrosion of this alloy follows the general principle of chemical reactions: rate of chemical reaction increases with increase in temperature.

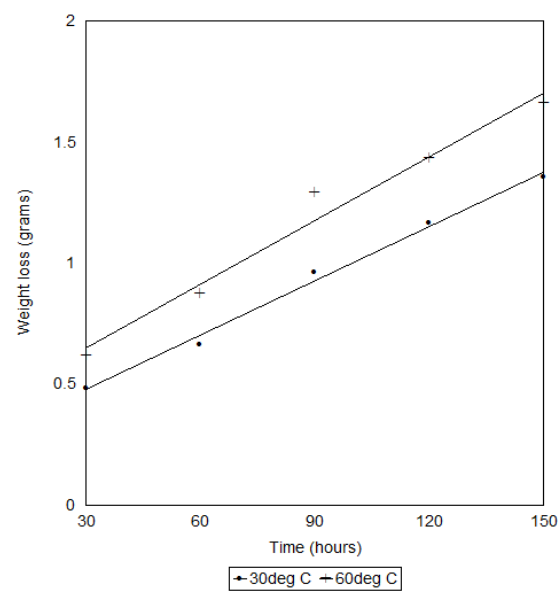

Figure 1. Effect of temperature on the weight loss of Al-Zn in $2 \mathrm{M} \mathrm{HCl}$.

\section{Weight loss and inhibition efficiency}

Weight loss measurement of aluminium - zinc alloy in $2 \mathrm{M} \mathrm{HCl}$ in the presence and absence of ocimum gratissimum at various concentrations after immersion for 150 hours at $30{ }^{\circ} \mathrm{C}$ is shown in Fig. 2; similar plots were obtained at $60{ }^{\circ} \mathrm{C}$. Weight loss of $\mathrm{Al}-\mathrm{Zn}$ decreases in the presence of the inhibitor and with increasing its concentration as well. Fig. 3 shows the variation of inhibition efficiency with time at various concentrations of ocimum gratissimum at $30{ }^{\circ} \mathrm{C}$. The inhibition efficiency increases with time and with increasing the 
concentration as well. This observation implies that the surface area of the alloy covered by the inhibitor increases as the concentration of the inhibitor increases.

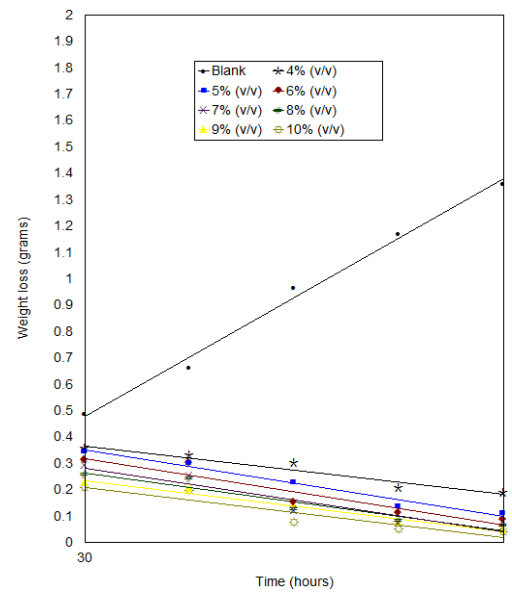

Figure 2. Variation of weight loss (grams) of $\mathrm{Zn}-\mathrm{Al}$ alloy in the absence and presence of ocimum gratissimum at $30{ }^{\circ} \mathrm{C}$ in $2 \mathrm{M} \mathrm{HCl}$.

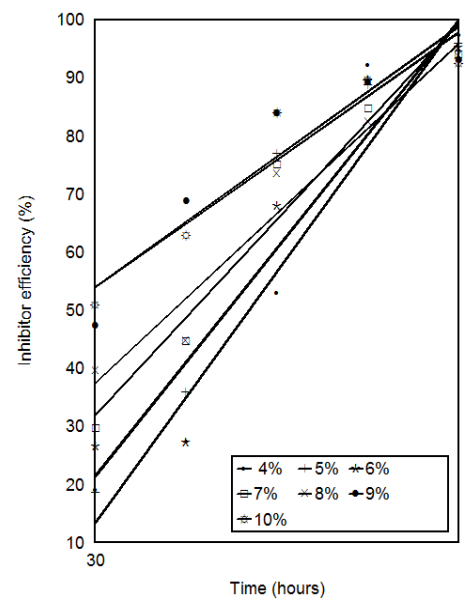

Figure 3. Variation of inhibitor efficiency (\%) with time in $2 \mathrm{M} \mathrm{HCl}$.

\section{Temperature dependence of inhibition efficiency}

Fig. 4 is the graphical representation of the temperature dependence of the inhibitor efficiency of ocimum gratissimum on the corrosion of $\mathrm{Al}-\mathrm{Zn}$ at $30{ }^{\circ} \mathrm{C}$ and $60{ }^{\circ} \mathrm{C}$ in $2 \mathrm{M} \mathrm{HCl}$. Fig. 4 shows that the inhibitor efficiency of ocimum gratissimum decreases with an increase in temperature, which suggests that the adsorption mechanism is physical.

The inhibitive effect of ocimum gratissimum may be attributed to the presence of phytochemical constituents of the plant seed extract. Previous studies on the phytochemical constituents of the plant have shown that it consists of alkaloids, tannins, flavonoids, phenols and glycoprotein [15]. These compounds contain nitrogen and oxygen atoms which possess lone pairs of electrons that may facilitate the formation of dative bonds acting as centres for adsorption, thus, creating a barrier between the alloy surface and the corrosive medium. 


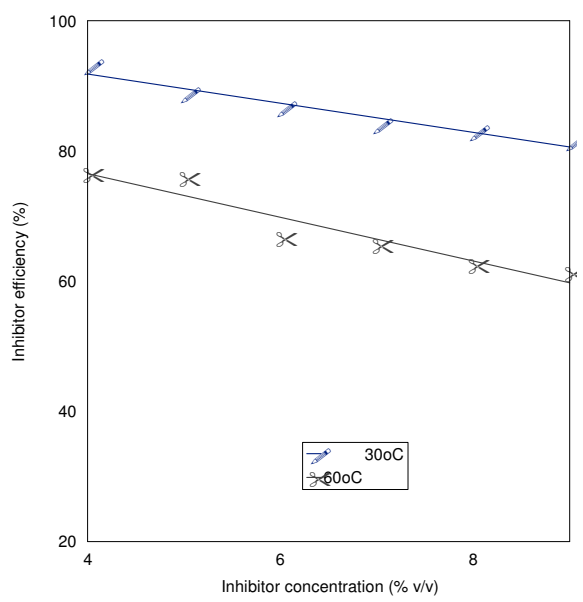

Figure 4. Temperature dependence of the inhibition efficiency.

\section{Adsorption isotherm of corrosion of $\mathrm{Al}-\mathrm{Zn}$ in $2 \mathrm{M} \mathrm{HCl}$}

The adsorption isotherm provides insight into the mechanism of corrosion inhibition. This is determined empirically by plotting the surface area of coverage $(S)$ as a function of the concentration of the inhibitor (Fig. 5). To ascertain the nature of adsorption, the surface coverage values for ocimum gratissimum extract at $30{ }^{\circ} \mathrm{C}$ and $60{ }^{\circ} \mathrm{C}$ were fitted into various adsorption isotherm models, and correlation coefficients $\left(\mathrm{R}^{2}\right)$ were used to determine the best fit which was obtained with Freundlich adsorption isotherm. The linear plots obtained $\left(\mathrm{R}^{2}=0.97\right)$ suggest that the experimental data fit the Freundlich adsorption isotherm which is given as equation (3) [16]

$$
\mathrm{S}=\mathrm{KC} \mathrm{C}^{\mathrm{n}}
$$

where

$$
\mathrm{S}<\mathrm{n}<1
$$

$$
\ln \mathrm{S}=\ln \mathrm{K}_{\mathrm{ads}}+\mathrm{n} \ln \mathrm{C}
$$

where $\mathrm{C}$ is the concentration of the ocimum gratissimum extract and $\mathrm{K}_{\mathrm{ads}}$ is the adsorption equilibrium constant; $\mathrm{n}$ and $\mathrm{K}_{\mathrm{ads}}$ are temperature dependent.

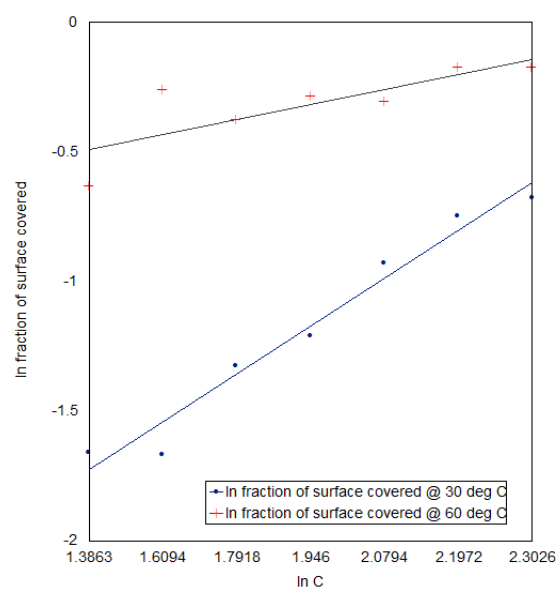

Figure 5. Freundlich isotherm for the corrosion inhibition of aluminium - zinc alloy in the presence of ocimum gratissimum extract. 


\section{Kinetic / thermodynamic treatment of weight loss results}

Assuming that the plot of corrosion rate $(\mathrm{CR})$ of $\mathrm{Zn}-\mathrm{Al}$ against concentration (C) of ocimum gratissimum (Fig. 6) obeys the kinetic relationship

$$
\log \mathrm{CR}=\log \mathrm{k}+\mathrm{B} \log \mathrm{C}
$$

where $\mathrm{k}$ is rate constant defined by the corrosion rate at inhibitor concentration of unity and B is reaction constant, measured for the inhibitor effectiveness [17-20]. The kinetic parameters $\mathrm{K}$ and $\mathrm{B}$ can be calculated from eq. 6. The slope B obtained is negative, (Table 1), depicting that the rate of corrosion is inversely proportional to the concentration of ocimum gratissium. This implies that ocimum gratissimum becomes more effective as the concentration increases. A high negative value of $\mathrm{B}$ implies good inhibitive properties for ocimum gratissimum. The free energy of the reaction can be calculated using the equation:

$$
\ln \mathrm{K}=\ln (55.5)^{-1}-\Delta \mathrm{G}_{\mathrm{ads}}(\mathrm{RT})^{-1}
$$

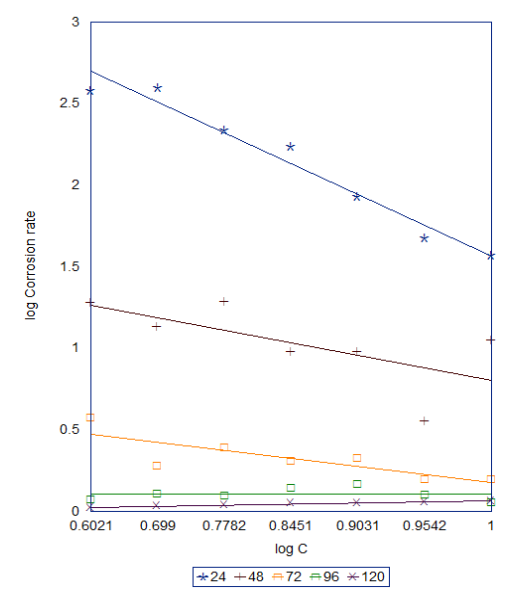

Figure 6. $\log$ corrosion rate versus log inhibitor concentration.

Table 1. Kinetic parameters for inhibitive effect of ocimum gratissium on the corrosion of $\mathrm{Zn}-\mathrm{Al}$ alloy in $2 \mathrm{M} \mathrm{HCl}$.

\begin{tabular}{ccc}
\hline $\begin{array}{c}\text { Concentration of ocimum } \\
\text { gratissimum \%(v/v) }\end{array}$ & Rate constant k $\left(\mathrm{s}^{-1}\right)$ & $\mathrm{B}$ \\
\hline Absence of inhibitor & -2.523 & \\
4 & 2.699 & -0.356 \\
5 & 2.398 & -0.291 \\
6 & 2.301 & -0.312 \\
7 & 2.301 & -0.355 \\
8 & 2.301 & -0.373 \\
9 & 2.222 & -0.385 \\
10 & 2.222 & -0.438 \\
\hline
\end{tabular}

The calculated values of the equilibrium constant $\mathrm{K}$ decrease with increasing temperature, which implies that the inhibitor is physically adsorbed by the metal. Values of the interaction parameter $\mathrm{N}$ obtained from the Freundlich isotherm 
(Table 2) are negative, which implies that there is repulsion on the adsorption layer.

The values of $\Delta \mathrm{G}_{\mathrm{ads}}$ (Table 2) for the reaction are negative and small. This implies that the adsorption of the inhibitor molecules is spontaneous. The magnitude of $\Delta \mathrm{G}_{\mathrm{ads}}$ is small and less than $-20 \mathrm{kJmol}^{-1}$, which suggests that ocimum gratissimum is physically adsorbed on the surface of the metal.

Corrosion reaction is an overall reaction in which both solid and liquid phases are consumed. Thus if the following equation ${ }^{18,20}$ is applied to corrosion rate

$$
\log \mathrm{W}_{\mathrm{i}}=\log \mathrm{W}_{0}-\mathrm{kt}
$$

where $\mathrm{k}$ is defined as the rate constant after time ( $\mathrm{t}$ ) of immersion, $\mathrm{W}_{\mathrm{i}}$ and $\mathrm{W}_{0}$ are weight losses in the presence and absence of the inhibitor. Fig.(7) shows a linear variation in the absence and presence of the inhibitor. This also confirms a first order kinetics. The rate constants, $\mathrm{k}$, obtained for the reaction are shown in Table 1.

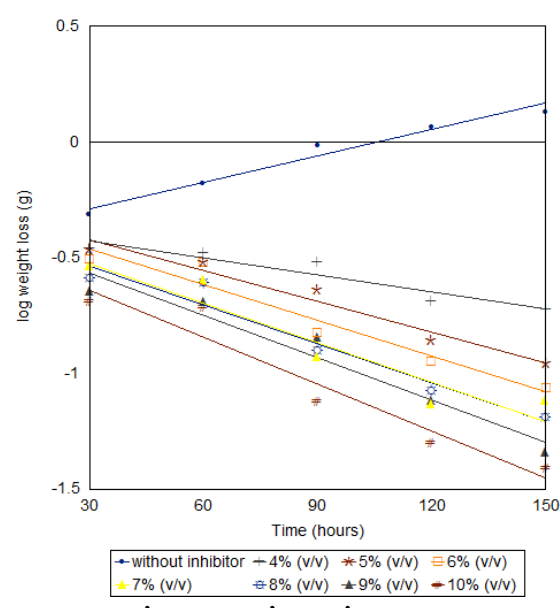

Figure 7. $\log$ of weight loss versus immersion time.

\section{Synergist effect of halide ions on ocimum gratissimum}

Fig. 8 shows that halide additive $\mathrm{KI}$ and $\mathrm{KCl}$ enhanced the inhibition efficiency of ocimum gratissimum at the temperature studied. This observation has been ascribed to the synergistic effect, which has been attributed to the formation of intermediate salt bridges by the halide (anions) between the metal surface and the positive end of the organic inhibitor [21-24]. Corrosion inhibition synergism from the increased surface coverage area arises from ion - pair interactions between the organic cations and the anions.

The synergistic parameter was calculated using the relationship given by Aramaki and Hackerman [25]

$$
S_{I}=\left(1-I_{1+2}\right)\left(1-i_{1+2}\right)^{-1}
$$

where $I_{1+2}=I_{1}$ is the inhibition efficiency of the halide, $I_{2}$ is the inhibition efficiency of ocimum gratissium extract and $I$ is the measured inhibition efficiency of the halide combined with ocimum gratissium extract. Values of $S_{\text {I }}$ less than 1 imply antagonistic interaction existing between halide ions and inhibitor. This may be attributed to competitive adsorption. $S_{I}$ values greater than 


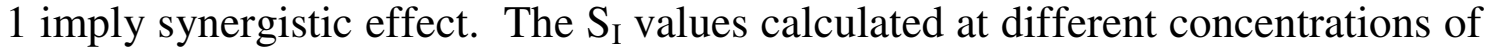
the inhibitor for this experiment (Table 3) are greater than 1, which implies that inhibition efficiency is enhanced by synergistic effect of iodide ions.

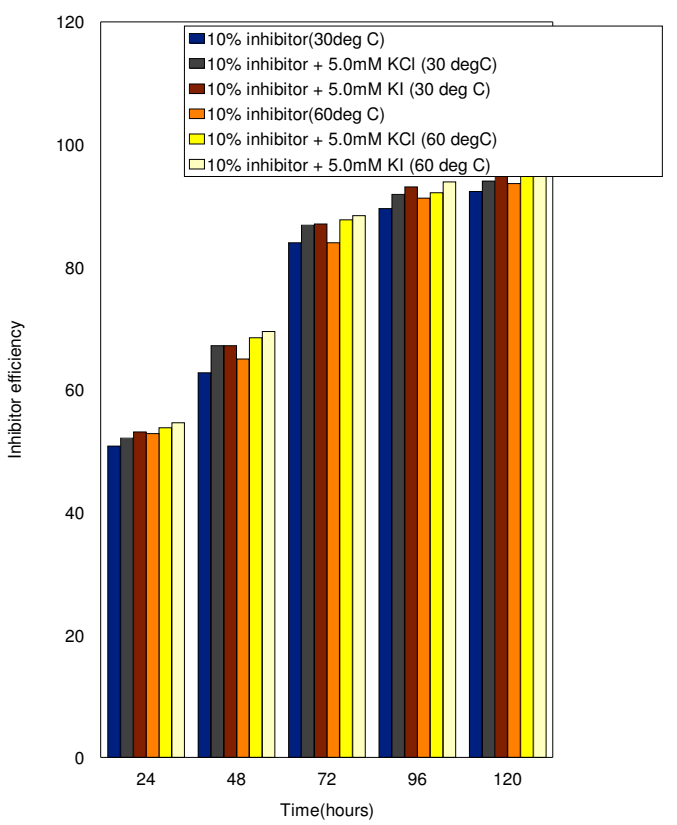

Figure 8. Effect of halide additives $(5.0 \mathrm{mM})$ on the inhibition efficiency of $10 \%$ ocimum gratissimum at different temperatures.

Table 2. Thermodynamic parameters for inhibitive effect of ocimum gratissium on the corrosion of $\mathrm{Zn}-\mathrm{Al}$ alloy in $2 \mathrm{M} \mathrm{HCl}$.

\begin{tabular}{cccc}
\hline \multirow{2}{*}{$\begin{array}{c}\text { Temperature } \\
\left({ }^{\circ} \mathrm{C}\right)\end{array}$} & $\begin{array}{c}\Delta \mathrm{G}_{\text {ads }}^{0} \\
\left(\mathrm{kJmol}^{-1}\right)\end{array}$ & $\begin{array}{c}\text { Equilibrium } \\
\text { constant } \mathrm{K}_{\mathrm{ads}}\end{array}$ & $\mathrm{N}$ \\
\cline { 2 - 4 } & -5.876 & 0.185 & -1.912 \\
60 & -3.227 & 0.058 & -0.548 \\
\hline
\end{tabular}

Table 3. Synergistic parameters $\left(\mathrm{S}_{\mathrm{I}}\right)$ for different concentrations of ocimum gratissimum extract.

\begin{tabular}{cc}
\hline $\begin{array}{c}\text { Concentrations of ocimum } \\
\text { gratissimum extract }(\% \mathrm{v} / \mathrm{v})\end{array}$ & $\mathrm{S}_{\mathrm{I}}$ \\
\hline 4 & 2.450 \\
6 & 2.141 \\
8 & 1.630 \\
10 & 1.408 \\
\hline
\end{tabular}

\section{Conclusions}

Extract from ocimum gratissium acts as an efficient inhibitor for $\mathrm{Al}-\mathrm{Zn}$ corrosion in $2 \mathrm{M} \mathrm{HCl}$. Corrosion of $\mathrm{Zn}-\mathrm{Al}$ decreases with temperature in the presence of inhibitor.

Inhibitor efficiency of ocimum gratissimum extracts increases with increase in concentration, but decreases with increase in temperature, which implies that the adsorption may be physical. Inhibition efficiency was enhanced by the addition 
of $\mathrm{KI}$ and $\mathrm{KC} 1$ while synergism decreases with increased concentration of inhibitor.

Adsorption of the extract on the surface as observed obeys Freundlich adsorption isotherm.

\section{References}

1. J. Randolph Kissel, Robert L. Ferry, Aluminium Studies: a guide to their specification and designs, $2^{\text {nd }}$ Ed: Link. (2002).

2. E. Paul Degarma, J.T. Black, Ronald A Kosher, Materials Processes in manufacturing, $9^{\text {th }}$ ed, Wiley Press, 133 (2003). ISBN 0- 471- 65653-4.

3. $\quad$ R.E. Sanders, J. Minerals 53 (2001) 21-25.

4. M.N.C. Ijeoma, Elements of corrosion and protection theory. Auto century publishing Co. Ltd, \t\ Enugu, 112 - 128 (1991).

5. C.E. Ekuma, N. E. Idenyi, Trends Appl. Sci. Research 2 (2007) 66-70.

6. C.E. Ekuma, N.E. Idenyi, A.E. Umahi, Informat. Tech. J. 7 (2007) 237-241.

7. S.A. Umoren, Port. Electrochim. Acta 26 (2007) 199-209.

8. A.Y. El-Etre, M. Abdallah, E. Tantawwy, Corros. Sci. 47 (2005) 385-387.

9. E.E. Oguzie, G.W. Onuoha, A.I. Onuchukwu, Mater. Chem. Phys. 89 (2004) 305.

10. A.Y. El-Etre, Corros. Sci. 45 (2003) 2485.

11. M. Abdallah, Port. Electrochim. Acta 22 (2004) 161-175.

12. S. Martinez, I. Stern, J. Appl. Electrochem. 31 (2001) 973-978.

13. E.E. Ebenso, U.J. Ibok, S.A. Umoren, O.K. Abiola, NC. Trans. SAEST 39 (2004) 117.

14. N.O. Eddy, S.A. Odoemelan, I.N. Ama, Green Chem. Letts. Rev. 3 (2010) 165-172.

15. H.O. Edeoga, O.O. Eriata, J. Med. Aromatic Plants Sci. 23 (2006) 224-349.

16. E.E. Oguzie, Corros. Sci. 49 (2007) 1527-1539.

17. E.A. Noor, Int. J. Electrochem. Sci. 2 (2007) 996-1017.

18. P.W. Atkins and J. Paula, Physical Chemistry, Oxford University Press, NY (2002).

19. J.M. Thomas, W.J. Thomas, Introduction to the principles of heterogeneous catalysis, $5^{\text {th }}$ ed., Academic Press, London (1981).

20. P.W. Atkins, Chemisorbed and physisorbed species, a textbook of Physical Chemistry, University Press, Oxford: NY, 936-938 (1980).

21. K.J. Laidler, Reaction kinetics, $1^{\text {st }}$ ed., vol. 1, Pergamon Press, New York (1963).

22. G. Mu, X. Li, J. Colloid Interface Sci. 289 (2005) 184-192.

23. D.Q. Zhang, L.X. Gao, G.D. Zhou, J. Appl. Electrochem. 33 (2003) 361366.

24. E.E. Oguzie, Y. Li, F.H. Wang, J. Colloid Interface Sci. 310 (2007) 90.

25. K. Aramaki, N. Hackerman, J. Electrochem. Soc. 116(5) (1969) 568-574. 